\title{
On Labor Productivity in OECD Countries: Panel Data Modeling
}

\author{
MOHAMED R. ABONAZEL ${ }^{1 *}$, OHOOD SHALABY ${ }^{2}$ \\ ${ }^{1}$ Department of Applied Statistics and Econometrics, Faculty of Graduate Studies for Statistical \\ Research, Cairo University, Giza, EGYPT \\ ${ }^{2}$ National Center for Social and Criminological Research, Cairo, EGYPT
}

\begin{abstract}
Labor productivity is a key measure of economic performance and an essential factor of improving the living standards. High labor productivity growth rate can reflect increased use of capital, and/or a decrease in the employment of low-productivity workers. Thus, it can be said that labor productivity indicators reflect the effectiveness of labor utilization, labor cost, and revenue accumulation. This paper studies the impact of labor market conditions, economic integration, market size, and institutional quality on labor productivity in Organization for Economic Co-operation and Development (OECD) countries during the period from 2005 to 2017 by using panel data technique. The study finds that the random effects panel data model is the appropriate model to fit this data. The results suggest that average annual hours worked, labor force participation rate, and inflation rate have a negative significant impact on labor productivity in OECD countries. However, annual growth rate of GDP per capita, value added of industry, and control of corruption have a positive significant impact on labor productivity.
\end{abstract}

Key-Words: - Fixed Effects Panel; GLS Estimation; Hausman Test; Labor Productivity; LSDV Estimation; Random Effects Panel; Within Group Estimation

Received: March 8, 2021. Revised: November 3, 2021. Accepted: November 13, 2021. Published: November 30, 2021.

\section{Introduction}

The OECD is an international organization that works with governments of 36 countries span the globe, from North and South America to Europe and Asia-Pacific. The OECD is also at the forefront of efforts to build better policies for better lives and to find evidence-based solutions to address social, economic and environmental challenges, starting from improving economic performance and creating jobs to fostering strong education and fighting international tax evasion.

Over the past years, productivity and economic growth have been an important focus of OECD work. Therefore, the OECD made strong efforts to improve the measurement of productivity growth. Now, there are different measures of labor productivity and the choice between them depends on the study purpose and data availability. One of the most widely used measures of productivity is Gross Domestic Product (GDP) per hour worked [1, $2,3]$. This measure captures the use of labor inputs better than just output per employee [4].

The size of labor force may be an opportunity to drive economic. The literatures prove that importance of labor factor in each phase of development in world economy. Irmatova [5] mentioned that "Long-term effects and shocks of the global financial crisis revealed that number one problem of the global economy was still unemployment", and "appropriate allocation and adequate qualification of labor ensure a smooth and productive functioning of economy".

Therefore, measuring labor productivity is important for public policy and private-sector decisionmaking. Labor productivity and labor utilization is considered assessment indicators of workforce performance. Country-level labor productivity reflects the efficiency of labor market in the economy.

Because of the above mentioned causes, it is important to study the determinants of labor productivity in OECD countries. The analysis of labor productivity in this study is based on some of factors: the effects of average annual hours worked, annual growth rate of labor compensation per hour worked, average wages, labor force participation rate, foreign direct Investment (FDI) inflows, annual growth rate of GDP per capita, inflation rate, value added of industry on labor productivity, and control of corruption.

The panel data technique plays an important role in the literature of analyzing determinants of labor productivity by combining the time series dimension and cross-section dimension in such a way that there are $(\mathrm{N})$ countries followed over $(\mathrm{T})$ time periods [6, $7,8,9,10]$. We will apply three panel data models. It is important to select appropriate model to fit this data. This choice is critical, as relying on 
inappropriate measures can lead to the design of inefficient incentives, wrong policy conclusions.

The paper is organized as follows: Section 2 provides the literature review about determinants of labor productivity. Section 3 and 4 presents the various estimation methods for static panel data models and some specification tests. Section 5 presents unit root test. Section 6 provides the empirical study on OECD countries. Finally, Section 7 offers the concluding remarks.

\section{Literature Reviews}

Some researchers found that labor productivity is not a solid, but a dynamic indicator due to rapid changes in global economic structural transformations. Many empirical studies are conducted about labor productivity that includes developed and developing countries for different periods. The focus of the literature is on OECD countries. Cui et al. [11] found that the leisure time had a dual effect on labor productivity by using panel data technique for 21 OECD countries during the period from 1980 to 2013. Moreover, leisure time was nonlinearly associated with labor productivity (inverted U-shaped). When leisure time reached the optimal level (5813 hours), leisure had a compensatory effect on work and can positively influence labor productivity, but when leisure time exceeded the optimal value, leisure had a substitution effect on work and can negatively influence labor productivity. Additionally, education time was also found to have a significant positive impact on labor productivity. Policardo et al. [12] linked the labor productivity with wage inequality by using Arellano-Bond estimator for dynamic panel data models for 34 OECD countries over the period from 1995 to 2007 . They found that large wage inequality was associated to lower labor productivity. In addition, the significant impact of GDP, hour worked per capita, and employment ratio on labor productivity. Serfraz [13] examined the effects of FDI inflows on respective labor productivity for a panel of seven major sectors in Pakistan's economy over the period from 1997 to 2016. All empirical tests concluded that FDI inflows positively affect labor productivity in case of Pakistan. Schubert and Neuhäusler [14] analyzed the hypothesis that the stagnating of the total factor productivities (TFP) trend was due to generally declining technological opportunities. Also, Choudhry [15] studied the impact of FDI with some other factors on labor productivity growth as "change in labor force participation, inflation rate, openness, information and communication technology (ICT) expenditure, gross capital formation, and urbanization" by using panel data approach for set of 45 countries over the period from 1980 to 2005 . The results revealed the positive significant impact of education, ICT investment, financial depth and FDI on labor productivity growth. However, increase in labor force participation, employment in agriculture sector andprice volatility have negative influence on the productivity growth. On the other hand, Abonazel and Shalaby [2] indicated that the labor force is one of the main factors that encourage FDI.

Korkmaz and Korkmaz [16] found unidirectional causality relationship from economic growth to labor productivity. Salinas-Jimenez and SalinasJimenez [17] interested in analyzing the relation between corruption and productivity levels in 22 OECD countries during the period from 1980 to 2000.

\section{Panel Data Models}

In econometrics literature, the panel data refer to the pooling of observations on a cross-section of households, countries, firms, etc. over several periods. Panel data have several advantages compared with either purely cross-sectional or purely time series data $[18,19]$. It is widely used to estimate dynamic econometric models compared with cross-section data. Its advantages over time series data include the possibility that underlying microeconomic dynamics may be obscured by aggregation biases, and the scope that panel data offer to investigate heterogeneity in adjustment dynamics between different types of individuals, household, or firms $[6,7,8]$.

\subsection{The Pooled Model}

\subsubsection{Model Specification}

A panel data regression differs from a regular timeseries or cross-section regression in that it has a double subscript on its variables, i.e.

$$
y_{i t}=\alpha+X_{i t} \beta+u_{i t} ; i=1, \ldots, N ; t=1, \ldots, T
$$

where is a scalar dependent variable, $\alpha$ is the intercept term, is Iobservation on $\mathrm{K}$ explanatory variables, is a vector of regression coefficients, is a scalar disturbance term, $\mathrm{i}$ denotes the cross-section dimension, $t$ denotes the time-series dimension. $\mathrm{N}$ is the number of cross- 
section units, and $\mathrm{T}$ is the number of time units. The model (1) can rewrite in the matrix form:

$$
\mathrm{y}=l_{\mathrm{NT}} \alpha+\mathrm{X} \beta+\mathrm{u}=\mathrm{Z}^{-},
$$

where $\mathrm{y}$ is a vector $(\mathrm{NT} \times 1)$ dimension, $\mathrm{X}$ is a matrix $(\mathrm{NT} \times \mathrm{K})$ dimension, $\mathrm{Z}=\left[l_{\mathrm{NT}}: \mathrm{X}\right], l_{\mathrm{NT}}$ is a vector of $(\mathrm{NT} \times 1)$ dimension and its all elements equal one, $\gamma=(\alpha, \beta)^{\prime} ; \quad \beta \quad$ is a vector with $(\mathrm{K} \times 1)$ dimension, and $\mathrm{u}$ is a vector $(\mathrm{NT} \times 1)$ dimension.

\subsubsection{Model Assumptions}

There are some assumptions of pooled model [20]:

A1. The model is linear in parameters.

$$
\text { A2. } \mathrm{E}\left(\mathrm{u}_{\mathrm{it}} \mid \mathrm{x}_{\mathrm{i} 1}, \ldots, \mathrm{x}_{\mathrm{iT}}\right)=0 \forall i, t
$$

A3. $\operatorname{var}\left(\mathrm{u}_{\mathrm{it}} \mid \mathrm{x}_{\mathrm{i} 1}, \ldots, \mathrm{x}_{\mathrm{iT}}\right)=\sigma_{\approx}^{2}$.

A4. $\operatorname{cov}\left(\mathrm{u}_{\mathrm{it}}, \mathrm{u}_{\mathrm{js}} \mid \mathrm{x}_{\mathrm{i} 1}, \ldots, \mathrm{x}_{\mathrm{iT}}\right)=0$ if $\mathrm{i} \neq \mathrm{j}$ or $\mathrm{t} \neq \mathrm{s}$.

A5. The explanatory variables are non-stochastic, independent of the errors, and such that

$(\mathrm{NT} \times(\mathrm{K}+1))$ matrix $\mathrm{Z}$ has a full column rank Matrix.

\subsubsection{Model Estimation}

In panel data models, the pooled least squares (LS) estimator is the best linear unbiased estimator (BLUE) under the classical assumptions (A1 to A5) as in the general linear regression model. The ordinary least squares (OLS) estimator of $\gamma$ in (2) is:

$$
\hat{\mathrm{YoLs}}_{\mathrm{O}}=\left(\mathrm{X}^{\prime} \mathrm{X}\right)^{-1} \mathrm{X}^{\prime} \mathrm{y}
$$

The variance-covariance matrix of Yous is:

$$
\operatorname{cov}\left(\hat{\gamma}_{\text {OLS }}\right)=\widehat{\sigma}_{\text {OLS }}^{2}\left(\mathrm{X}^{t} \mathrm{X}\right)^{-1},
$$

with

$$
\widehat{\sigma}_{\mathrm{OLS}}^{2}=\frac{\widehat{\mathrm{u}}_{\mathrm{OLS}}^{J} \widehat{\mathrm{U}}_{\mathrm{OLS}}}{\mathrm{NT}-\mathrm{K}} .
$$

\subsection{Fixed Effects Model}

\subsubsection{Model Specification}

The main advantage of a panel data is that it allows the researcher great flexibility in modeling differences in behaviour across individuals. The Fixed Effects (FE) model is also called (the individual-specific effects model) which allows each cross-sectional unit to have a different intercept term though all slopes are the same [21]. The FE model in the general form can write as:

$$
y_{i t}=\alpha_{i}+X_{i t} \beta+u_{i t}
$$

The model (3) can rewrite in the matrix form:

$$
y=\mathrm{D} \underline{\alpha}+\mathrm{X} \beta+\mathrm{u},
$$

where

$$
\underline{\alpha}^{\prime}=\left(\alpha_{1, \ldots,} \alpha_{\mathrm{N}}\right)
$$

and

$\mathrm{D}=\mathrm{I}_{\mathrm{N}} \otimes l_{\mathrm{T}}=\left(\begin{array}{llll}\mathrm{d}_{1} & \mathrm{~d}_{2} & \cdots & \mathrm{d}_{\mathrm{N}}\end{array}\right)$; where $\mathrm{D}$ is a matrix with $(\mathrm{NT} \times \mathrm{N})$ dimension, which included all dummy variables for all cross-sectional units, $l_{\mathrm{T}}$ is a vector of dimension $(T \times 1)$ and its all elements equal one, $\mathrm{d}_{\mathrm{i}}$ is a dummy variable indicating for crosssectional unit (i), $\otimes$ denotes to kronecker product, and $\underline{\alpha}$ is a vector with $(\mathrm{N} \times 1)$ dimension. It can easily be verified that the following properties hold [22]:
a. $\quad \mathrm{D} l_{\mathrm{T}}=l_{\mathrm{N}} \otimes l_{\mathrm{T}}=l_{\mathrm{NT}}$
b. $\mathrm{D}^{\prime} \mathrm{D}=\mathrm{TI}_{\mathrm{N}}$.
c. $\quad \mathrm{DD}^{\prime}=\mathrm{I}_{\mathrm{N}} \otimes l_{\mathrm{T}} l_{\mathrm{T}}^{\prime}$
d. $\frac{1}{\mathrm{~T}} \mathrm{D}^{\prime} \mathrm{y}=\left(\overline{\mathrm{y}}_{1}, \cdots, \overline{\mathrm{y}}_{\mathrm{N}}\right)^{\prime}$.
e. $\frac{1}{\mathrm{~T}} \mathrm{D}^{\prime} \mathrm{X}=\left(\overline{\mathrm{X}}_{1,}, \ldots, \overline{\mathrm{X}}_{\mathrm{N}}\right)^{\prime}$.

where

$$
\bar{y}_{i}=\frac{\sum_{\mathrm{t}=1}^{\mathrm{T}} \mathrm{yit}_{\mathrm{it}}}{\mathrm{T}}
$$

and

$$
\overline{\mathrm{X}}_{\mathrm{i},}^{\prime}=\left(\overline{\mathrm{X}}_{\mathrm{i} 1}, \ldots, \overline{\mathrm{X}}_{\mathrm{ik}}\right)=\left(\frac{\sum_{\mathrm{t}=1}^{\mathrm{T}} \mathrm{x}_{\mathrm{it} 1}}{\mathrm{~T}}, \ldots, \frac{\sum_{\mathrm{t}=1}^{\mathrm{T}} \mathrm{X}_{\mathrm{itk}}}{\mathrm{T}}\right) .
$$

\subsubsection{Model Assumptions}


To complete the specification of this model, we adopt the above assumptions except assumption A5, it has become:

A5. The explanatory variables are non-stochastic, independent of the errors, and such that

$(\mathrm{NT} \times(\mathrm{N}+\mathrm{K}))$ matrix $\mathrm{Z}^{\mathrm{F}}=[\mathrm{D} ; \mathrm{X}]$ has a full column rank matrix.

\subsubsection{Model Estimation}

\section{Least squares dummy variables (LSDV) estimator}

This estimator depends on the dummy variable technique, if we have $(\mathrm{N})$ countries, we will used (N-1) dummies to avoid the dummy-variable trap (i.e., multicollinearity problem, see [23, 24]). The "least squares" part of the name refers to the method used to estimate the model, not to the model itself.

The estimator of $\beta$ can be obtained by OLS on the transformed data $\mathrm{y}^{*}=\mathrm{M}_{\mathrm{D}} \mathrm{Y}$ and $\mathrm{X}^{*}=\mathrm{M}_{\mathrm{D}} \mathrm{X}$. The transformed variables are simply the original variables expressed as deviations from the individual mean $[20,22]$. Therefore, in a particular case, just account:

$$
\mathrm{y}_{\mathrm{it}}-\overline{\mathrm{y}}_{\mathrm{i}}=\left(\mathrm{X}_{\mathrm{it}}^{t}-\overline{\mathrm{X}}_{\mathrm{i}}^{v}\right) \beta+\mathrm{u}_{\mathrm{it}}^{*} .
$$

The OLS estimator of $\beta$ in (3) is

$$
\widehat{\beta}_{\mathrm{LSDV}}=\left(\mathrm{X}^{\prime} \mathrm{M}_{\mathrm{D}} \mathrm{X}\right)^{-1} \mathrm{X}^{t} \mathrm{M}_{\mathrm{D}} \mathrm{Y}
$$

where

$$
\mathrm{M}_{\mathrm{D}}=\left[\begin{array}{ccc}
\mathrm{M}_{0} & \cdots & 0 \\
\vdots & \ddots & \vdots \\
0 & \cdots & \mathrm{M}_{0}
\end{array}\right]=\mathrm{I}_{\mathrm{NT}}-\mathrm{D}\left(\mathrm{D}^{\prime} \mathrm{D}\right)^{-1} \mathrm{D}^{\prime}
$$

with $\mathrm{M}_{0}=\mathrm{I}_{\mathrm{T}}-\mathrm{T}^{-1} l_{\mathrm{T}} l_{\mathrm{T}}^{v}$, where $\mathrm{M}_{\mathrm{D}}$ is idempotent matrix with $(\mathrm{NT} \times \mathrm{NT})$ dimension, $\mathrm{M}_{0}$ is idempotent matrix with $(\mathrm{T} \times \mathrm{T})$ dimension, and $\mathrm{I}_{\mathrm{NT}}$ and $\mathrm{I}_{\mathrm{T}}$ are identity matrices with $(\mathrm{NT} \times \mathrm{NT}),(\mathrm{T} \times \mathrm{T})$ dimension, respectively.
The OLS estimator of $\alpha_{i}$ in (3) is

$$
\widehat{\alpha}_{i L S D V}=\bar{y}_{i}-\bar{X}_{i}^{z} \hat{\beta}_{L S D V} ; \forall i=1, \ldots, N
$$

The variance-covariance matrices of $\widehat{\beta}_{\mathrm{LSDV}}$ and $\widehat{\alpha}_{\mathrm{LSDV}}$ are

$$
\operatorname{cov}\left(\widehat{\beta}_{\mathrm{LSDV}}\right)=\widehat{\sigma}^{2}{ }_{\mathrm{LSDV}}\left(\mathrm{X}^{t} \mathrm{M}_{\mathrm{D}} \mathrm{X}\right)^{-1}
$$

$\operatorname{cov}\left(\widehat{\alpha}_{\mathrm{iLSDV}}\right)=\mathrm{T}^{-1} \widehat{\mathrm{\sigma}}_{\mathrm{LSDV}}^{2}+\overline{\mathrm{X}}_{\mathrm{i}, \mathrm{c}}^{f} \operatorname{cov}\left(\widehat{\beta}_{\mathrm{LSDV}}\right) \overline{\mathrm{X}}_{\mathrm{i},}^{t}$

where

$$
\widehat{\mathrm{\sigma}}_{\mathrm{LSDV}}^{2}=\frac{\widetilde{\mathrm{u}}_{\mathrm{LSDV}}^{\mathrm{N}} \mathrm{\widehat { \textrm {L } } \mathrm { LSDV }}}{\mathrm{NT}-\mathrm{N}-\mathrm{K}} ; \hat{\mathrm{u}}_{\mathrm{LSDV}}=\mathrm{M}_{\mathrm{D}} \mathrm{Y}-\mathrm{M}_{\mathrm{D}} \mathrm{X} \widehat{\beta}_{\mathrm{LSDV}} .
$$

\section{Fixed Effects Within Group Estimator}

The within group estimator is based on the idea of measuring the association between individualspecific deviations of regressors from their timeaveraged values and individual-specific deviations of the dependent variable from its time-averaged value [21]. The within group estimator of $\beta$ is:

$$
\hat{\beta}_{\mathrm{w}}=\left(\mathrm{S}_{\mathrm{XX}}\right)^{-1} \mathrm{~S}_{\mathrm{Xy}}
$$

where $\mathrm{S}_{\mathrm{XX}}=\sum_{\mathrm{i}=1}^{\mathrm{N}} \sum_{\mathrm{t}=1}^{\mathrm{T}}\left(\mathrm{X}_{\mathrm{it}}-\overline{\mathrm{X}}_{\mathrm{i}}\right)\left(\mathrm{X}_{\mathrm{it}}-\overline{\mathrm{X}}_{\mathrm{i}}\right)^{\prime}$ and

$\mathrm{S}_{\mathrm{Xy}}=\sum_{\mathrm{i}=1}^{\mathrm{N}} \sum_{\mathrm{t}=1}^{\mathrm{T}}\left(\mathrm{X}_{\mathrm{it}}-\overline{\mathrm{X}}_{\mathrm{i}}\right)\left(\mathrm{y}_{\mathrm{it}}-\overline{\mathrm{y}}_{\mathrm{i}}\right)^{\prime}$

The within group estimator is the OLS estimator of model (3). A special feature of this estimator is that it yields consistent estimates of $\beta$ in the LSDV approach, whereas the pooled OLS estimators do not.

\subsection{Random Effects Model}

\subsubsection{Model Specification}

A more precise term for the Random Effects (RE) model is the one-way individual-specific RE model, or more simply is the random intercept model, another name is the error components model. 
Unlike the FE model, in which allow each crosssectional unit to have its own (fixed) intercept value, the RE model supposed that the intercept values are a random drawing from a much bigger population. There are many parameters in the FE model and the

loss of degrees of freedom can be avoided if the $\alpha_{i}$ can be assumed random. The basic idea of RE model is to start with model (3) instead of treating

$\alpha_{i}$ as fixed, we assume that it is a random variable

with the (common) intercept $\alpha$ which represents the mean value of all the (cross-sectional) intercepts and the error component $\mu_{\mathrm{i}}$ represents the (random) deviation of individual intercept from this mean value. However, that $\mu_{\mathrm{i}}$ is not directly observable; it is known as an unobservable, or latent, variable [18]. The intercept for an individual can be expressed as:

$$
\alpha_{i}=\alpha+\mu_{i} ; \quad i=1,2, \ldots, N \text {, }
$$

where the component $\mu_{i}$ in (4) is the random heterogeneity specific to $i^{\text {th }}$ observation and is constant through time. And $\mu_{\mathrm{i}}$ is with a mean value of zero and variance $\sigma_{\mu}^{2}$.

From (4), the RE model is given by

$$
y_{i t}=\alpha+X_{i t} \beta+\omega_{i t} ; \omega_{i t}=\mu_{i}+u_{i t} .
$$

The RE model in (5) is called the composite error term consists of two components:

- $\mu_{\mathrm{i}}$ is the cross-section, or individual-specific error component, accounting for unobservable factors affecting y and which do not vary over time.

- $\mathrm{u}_{\mathrm{it}}$ is the combined time series and crosssection error component, represents the other variables influencing y but which vary both over time and individuals.

Stacking all the observations related to the individual i, we get:

$$
\mathrm{y}_{\mathrm{i}}=\mathrm{Z}_{\mathrm{i}} \gamma+\omega_{\mathrm{i}} \text {, }
$$

where $y_{i}=\left(y_{i 1}, \ldots, y_{i T}\right)^{x}, \quad Z_{i}$ is the matrix of observations of the explanatory variables (including the constant term), $\gamma=(\alpha, \beta)^{\prime}$, and $\omega_{\mathrm{i}}$ is the vector of the disturbances for the $\mathrm{it}^{\text {th }}$ individual. Stacking the model in (6) related to the time period t, we get

$$
y=Z \gamma+\omega .
$$

\subsubsection{Model Assumptions}

The usual assumptions of the RE model are [20, 21]:

B1. $\mathrm{E}\left(\mu_{\mathrm{i}} \mid \mathrm{x}_{\mathrm{i} 1}, \ldots, \mathrm{x}_{\mathrm{iT}}\right)=0, \forall \mathrm{i}$.

B2. $\operatorname{var}\left(\mu_{\mathrm{i}} \mid \mathrm{x}_{\mathrm{i} 1}, \ldots, \mathrm{x}_{\mathrm{iT}}\right)=\sigma_{\mu}^{2}, \forall \mathrm{i}$.

B3. $E\left(\mu_{\mathrm{i}} \mu_{\mathrm{j}} \mid \mathrm{x}_{\mathrm{i} 1}, \ldots, \mathrm{x}_{\mathrm{iT}}\right)=0$; if $(\mathrm{i} \neq \mathrm{j})$.

B4. $\mathrm{E}\left(\mathrm{u}_{\mathrm{it}} \mid \mathrm{x}_{\mathrm{i} 1}, \ldots, \mathrm{x}_{\mathrm{iT}}\right)=0, \forall \mathrm{i}, \mathrm{t}$.

B5. $\operatorname{var}\left(\mathrm{u}_{\mathrm{it}} \mid \mathrm{x}_{\mathrm{i} 1, \ldots,} \mathrm{x}_{\mathrm{iT}}\right)=\sigma_{\mathrm{u}}^{2}, \forall \mathrm{i}$, t.

B6. $\mathrm{E}\left(\mathrm{u}_{\mathrm{it}} \mathrm{u}_{\mathrm{js}} \mid \mathrm{x}_{\mathrm{i} 1}, \ldots, \mathrm{x}_{\mathrm{iT}}\right)=0$ if $(\mathrm{i} \neq \mathrm{j}$ or $\mathrm{t} \neq \mathrm{s})$;

B7. $\mathrm{E}\left(\mathrm{u}_{\mathrm{it}} \mu_{\mathrm{i}} \mid \mathrm{x}_{\mathrm{i} 1}, \ldots, \mathrm{x}_{\mathrm{iT}}\right)=0, \forall \mathrm{i}$, t.

That is, the individual error components are not correlated with each other, are not auto-correlated across both cross-section, and time series units. As a result of assumptions (B1 to B7):

B8. $E\left(\omega_{i t} \mid x_{i 1}, \ldots, x_{i T}\right)=0$.

B9. $\operatorname{var}\left(\omega_{\mathrm{it}} \mid \mathrm{x}_{\mathrm{i} 1}, \ldots, \mathrm{x}_{\mathrm{iT}}\right)=\sigma_{\mu}^{2}+\sigma_{\mathrm{u}}^{2}$.

B10. $\mathrm{E}\left(\omega_{\mathrm{it}} \omega_{\mathrm{is}} \mid \mathrm{x}_{\mathrm{i} 1}, \ldots, \mathrm{x}_{\mathrm{iT}}\right)=\sigma_{\mu}^{2}$, if $(\mathrm{t} \neq \mathrm{s})$.

B11. $E\left(\omega_{i t} \omega_{j s} \mid x_{i 1}, \ldots, x_{i T}\right)=0$, if $(i \neq j)$.

\subsubsection{Model Estimation}

In general, the error components model appears with a particular pattern of serial correlation in the disturbances. The OLS estimators are still unbiased and consistent but inefficient. It is also much well- 
known that the most appropriate method in this model is the generalized least squares (GLS)

method [25]. The GLS estimators of $\gamma$ in (7) is

$\hat{\mathrm{Y}}_{\mathrm{GLS}}=\left(\mathrm{Z}^{\prime} \Omega^{-1} \mathrm{Z}\right)^{-1} \mathrm{Z}^{\prime} \Omega^{-1} \mathrm{y}$

where $\Omega=\mathrm{I}_{\mathrm{NT}}+\frac{\sigma_{\mu}^{\frac{\pi}{\mu}}}{\sigma_{\mathrm{u}}^{2}}\left(\mathrm{I}_{\mathrm{N}} \otimes l_{\mathrm{T}} l_{\mathrm{T}}^{\prime}\right)$.

The variance-covariance matrix of $\widehat{Y}_{\mathrm{GLS}}$ is

$$
\operatorname{cov}\left(\hat{Y}_{\mathrm{GLS}}\right)=\sigma_{\mathrm{u}}^{2}\left(\mathrm{Z}^{\prime} \Omega^{-1} \mathrm{Z}\right)^{-1} .
$$

\section{Specification Tests}

\subsection{Testing Significance of the Group Effect}

In the model (3), it can test the hypothesis that $\alpha_{i}$ equals zero for one specific group by using the $t$ ratio, however, is typically not useful for testing in this regression context. If we are interested in differences across groups, we can use $\mathrm{F}$ ratio to test the hypothesis that the constant terms are all equal [20]:

$$
\mathrm{H}_{0}: \alpha_{1}=\cdots=\alpha_{\mathrm{N}}
$$

$\mathrm{H}_{1}$ : At least on of $\alpha_{\mathrm{i}}$ is different.

The F statistic of this test is

$$
\mathrm{F}_{(\mathrm{N}-1, \mathrm{NT}-\mathrm{N}-\mathrm{K})}=\frac{\left(\mathrm{R}_{\mathrm{LSDV}}^{\mathrm{Z}}-\mathrm{R}_{\mathrm{OLS}}^{\mathrm{I}}\right) /(\mathrm{N}-1)}{\left(1-\mathrm{R}_{\mathrm{LSDV}}^{\mathrm{z}}\right) /(\mathrm{NT}-\mathrm{N}-\mathrm{K})},
$$

where $R_{\text {OLS }}^{2}$ and $R_{\mathrm{LSDV}}^{2}$ are the coefficients of determination of the pooled and FE models, respectively. If the null hypothesis is rejected, then there is a statistically significant group effect, i.e. the pooled model does not fit the data.

\subsection{Lagrange Multiplier Test}

Breusch and Pagan [26] devised the Lagrange Multiplier (LM) test for the RE model based on the OLS residuals. The null hypothesis of LM test is "the pooled OLS estimator is adequate" against "the RE alternative":

$$
\mathrm{H}_{0}: \sigma_{\mu}^{2}=0 \text { vs. } \mathrm{H}_{1}: \sigma_{\mu}^{2} \neq 0 \text {. }
$$

The test statistic is

$$
\mathrm{LM}=\frac{\mathrm{NT}}{2(\mathrm{~T}-1)}\left(\frac{\sum_{\mathrm{i}=1}^{\mathrm{N}}\left(\sum_{\mathrm{t}=1}^{\mathrm{T}} \widehat{\mathrm{u}}_{\mathrm{it}}\right)^{\mathrm{z}}}{\sum_{\mathrm{i}=1}^{\mathrm{N}} \Sigma_{\mathrm{t}=1}^{\mathrm{T}} \hat{\mathrm{u}}_{\mathrm{it}}^{\mathrm{z}}}-1\right)^{2},
$$

where $\hat{\mathrm{u}}_{\mathrm{it}}$ is the pooled OLS residuals. Under the null hypothesis, the limiting distribution of LM is chi-squared with one dimension of freedom. If the null hypothesis is rejected, then the pooled model does not fit the data.

\subsection{Hausman Specification Test}

One of the most controversy assumptions underlying the RE model is the absence of correlation between the regressors and the individual effects. Indeed, in many circumstances, this is a quite untenable assumption. It is then important to check for the validity of this assumption; as such, a correlation would lead to the inconsistency of most of the estimators of the error components model. Hausman specification test [27] is the most commonly used specification test for uncorrelated effects.

The hypotheses of Hausman specification test are

$\mathrm{H}_{0}: \beta_{\mathrm{FE}}=\beta_{\mathrm{RE}}$ are consistent; but only $\beta_{\mathrm{RE}}$ is efficient

$\mathrm{H}_{1}: \beta_{\mathrm{FE}}$ is consistent and $\beta_{\mathrm{RE}}$ is inconsistent.

The Hausman test is a kind of Wald chi-squared test with (K-1) degree of freedom. The Wald chisquared statistic is

$$
\mathrm{H}=\left(\widehat{\beta}_{\mathrm{FE}}-\widehat{\beta}_{\mathrm{RE}}\right)^{\prime}\left(\operatorname{var}\left(\widehat{\beta}_{\mathrm{FE}}\right)-\operatorname{var}\left(\widehat{\beta}_{\mathrm{RE}}\right)\right)^{-1}\left(\widehat{\beta}_{\mathrm{FE}}-\widehat{\beta}_{\mathrm{RE}}\right) .
$$

If the null hypothesis is rejected, the conclusion is that the RE model is not appropriate because the RE is probably correlated with one or more regressors.

\section{Unit Root Test}


Before conducting econometric analyses, we have to examine the stationary of the variables by using a unit root test, because the estimation processes that employ non-stationary data can lead to misleading inferences. In addition, panel data are subject to volatility because of the presence of individual differences between cross-sectional units in the panel. Assuming the following model:

$y_{i t}=\alpha_{i}+\rho_{i} y_{i, t-1}+u_{i t}$

where $\rho_{i}$ is the autocorrelation parameter for each cross-sectional unit. The null and alternative hypotheses are defined as

\section{$\mathrm{H}_{0}$ : All panels contain unit roots}

\section{$\mathrm{H}_{1}$ : At least one panel is stationary}

There are several unit root tests for panel data; however, Levin-Lin-Chu (LLC), Im-Pesaran-Shin (IPS) and Fisher-type tests (Fisher) are the most widely used to test panel unit roots. Here, we will focus on Fisher test which proposed by Maddala and $\mathrm{Wu}$ [28], because it does not require a balanced panel, so $\mathrm{T}$ can differ over cross-sections. The test statistic of Fisher test is

$$
\mathrm{MW}=-2 \sum_{\mathrm{i}=1}^{\mathrm{N}} \log \left(\mathrm{p}_{\mathrm{i}}\right)
$$

where $\mathrm{p}_{\mathrm{i}}$ is the $\mathrm{p}$-value from the $\mathrm{i}^{\mathrm{ith}}$-test in each cross section such that $\mathrm{p}_{\mathrm{i}}$ are $\mathrm{U}(0,1)$ and independent, and
MW has a chi-square distribution with $(2 \mathrm{~N})$ degree of freedom.

\section{Empirical Study}

This paper is interested in examining the significant impact of ten factors on Labor productivity by using annual data for 36 OECD countries over the period from 2005 to 2017. The dataset is limited by the amount of information available for each country involved. STATA software (version 16) was used to perform our analysis.

\subsection{Data Description}

Table 1 presents the definitions of the variables used in our study. Based on what was published in OECD [4], Labor productivity is the most frequently computed productivity indicator. It shows the volume of output produced per unit of labor input. The ratio between output and labor inputs depends on the degree of the existence of other inputs, such as physical capital and increasingly fixed assets used in production, and technical efficiency and organizational change.

According to the literature mentioned above, the relationship between Labor Productivity and its determinants can be estimated by the following equation:

$$
\mathrm{LP}=f\left(\begin{array}{c}
\mathrm{HW}, \mathrm{LCH}, \mathrm{WAG}, \mathrm{LFP}, \\
\text { FDI, GDPC,INF, } \\
\text { IND, COR }
\end{array}\right)+\text { Error. }
$$

Table 1. Definition of the variables

\begin{tabular}{|c|l|l|}
\hline Variable & \multicolumn{1}{|c|}{ Definition } & Measuring Unit \\
\hline LP & $\begin{array}{l}\text { Labor productivity, measured as GDP per hour worked. GDP is } \\
\text { measured as gross value added in market prices. Labor input is } \\
\text { defined as total hours worked of all persons engaged in production. } \\
\text { This indicator is measured in US dollars (constant prices 2010 and } \\
\text { Purchasing Power Parities PPPs) and indices. Source: OECD [4], } \\
\text { GDP per hour worked (indicator). doi: 10.1787/1439e590-en }\end{array}$ & US\$ \\
\hline $\mathbf{H W}$ & $\begin{array}{l}\text { Average annual hours worked is defined as the total number of hours } \\
\text { actually worked per year divided by the average number of people in } \\
\text { employment per year. Actual hours worked include regular work } \\
\text { hours of full-time, part-time and part-year workers, paid and unpaid } \\
\text { overtime, hours worked in additional jobs, and exclude time not }\end{array}$ & Hours/Worker \\
\hline
\end{tabular}




\begin{tabular}{|c|c|c|}
\hline & $\begin{array}{l}\text { worked because of public holidays, annual paid leave, own illness, } \\
\text { injury and temporary disability, maternity leave, parental leave, } \\
\text { schooling or training, slack work for technical or economic reasons, } \\
\text { strike or labor dispute, bad weather, compensation leave and other } \\
\text { reasons. The data cover employees and self-employed workers. This } \\
\text { indicator is measured in terms of hours per worker per year. } \\
\text { Data on total hours worked is computed using surveys carried out on } \\
\text { households or enterprises [29]. Source: OECD [4], Hours worked } \\
\text { (indicator). doi: } 10.1787 / 47 \text { be1c78-en }\end{array}$ & \\
\hline LCH & $\begin{array}{l}\text { Annual growth rate of labor compensation per hour worked. Labor } \\
\text { compensation per hour worked is defined as compensation of } \\
\text { employees in national currency divided by total hours worked by } \\
\text { employees. Source: OECD [4], Labour compensation per hour } \\
\text { worked (indicator). doi: } 10.1787 / 251 \text { ec } 2 \text { da-en }\end{array}$ & $\%$ \\
\hline WAG & $\begin{array}{l}\text { Average wages are obtained by dividing the national-accounts-based } \\
\text { total wage bill by the average number of employees in the total } \\
\text { economy, which is then multiplied by the ratio of the average usual } \\
\text { weekly hours per full-time employee to the average usually weekly } \\
\text { hours for all employees. This indicator is measured in USD constant } \\
\text { prices using } 2016 \text { base year and PPPs for private consumption of the } \\
\text { same year. Source: OECD [4], Average wages (indicator). doi: } \\
10.1787 / \text { cc3e1387-en }\end{array}$ & US\$ \\
\hline LFP & $\begin{array}{l}\text { Labor force participation rate is the proportion of the population ages } \\
15-64 \text { that is economically active: all people who supply labor for the } \\
\text { production of goods and services during a specified period. } \\
\text { Source: https://data.worldbank.org/indicator/SL.TLF.CACT.ZS. } \\
\text { Data retrieved in September } 2018\end{array}$ & $\begin{array}{l}\% \text { of total population } \\
\text { ages } 15-64\end{array}$ \\
\hline FDI & $\begin{array}{l}\text { Net FDI Inflows. } \\
\text { Source: ttps://data.worldbank.org/indicator/BX.KLT.DINV.CD.WD }\end{array}$ & Current Billion US\$ \\
\hline GDPC & $\begin{array}{l}\text { Annual growth rate of GDP per capita, GDP per capita is gross } \\
\text { domestic product divided by midyear population. } \\
\text { Source: https://data.worldbank.org/indicator/NY.GDP.PCAP.KD.ZG }\end{array}$ & $\%$ \\
\hline INF & $\begin{array}{l}\text { Inflation Rate is the annual percentage change of consumer prices. } \\
\text { Source: } \\
\text { https://data.worldbank.org/indicator/FP.CPI.TOTL.ZG?locations=AE }\end{array}$ & $\%$ \\
\hline IND & $\begin{array}{l}\text { Value added of industry, comprises value added in mining, } \\
\text { manufacturing, construction, electricity, water, and gas. Value added } \\
\text { is the net output of a sector after adding up all outputs and subtracting } \\
\text { intermediate inputs. It is calculated without making deductions for } \\
\text { depreciation of fabricated assets or depletion and degradation of } \\
\text { natural resources. } \\
\text { Source: https://data.worldbank.org/indicator/NV.IND.TOTL.ZS }\end{array}$ & $\%$ of GDP \\
\hline COR & $\begin{array}{l}\text { Control of Corruption reflects perceptions of the extent to which } \\
\text { public power is exercised for private gain. } \\
\text { Source: https://info.worldbank.org/governance/wgi/\#home. }\end{array}$ & $\begin{array}{l}\text { Ranges from } \\
-2.5 \text { (weak) to } 2.5 \\
\text { (strong) governance } \\
\text { performance }\end{array}$ \\
\hline
\end{tabular}

Figure 1 shows the labor productivity for all OECD countries during the period from 2005 to 2017 based on OECD database.

Table 2 presents some descriptive statistics of all variables. Table 2 shows that the mean of LP in the OECD countries reaches to (44.3) US\$ during the period from 2005 to 2017 . Figure 2 presents the mean of LP in each country during the period of study. We notice that Luxembourg and Norway have the highest LP among OECD countries with mean (80.06) and (78.07) US\$ respectively over all the period, while Mexico has the lowest LP with mean (18.45) US\$. 
Figure 3 presents the LP in OECD countries over the period from 2005 to 2017 . We notice that the LP in most of OECD countries grows slowly. Unlike some countries that have witnessed a significant increase in the LP, for example Ireland, where increased from (51.64) in 2005 to (85.99) in 2017.

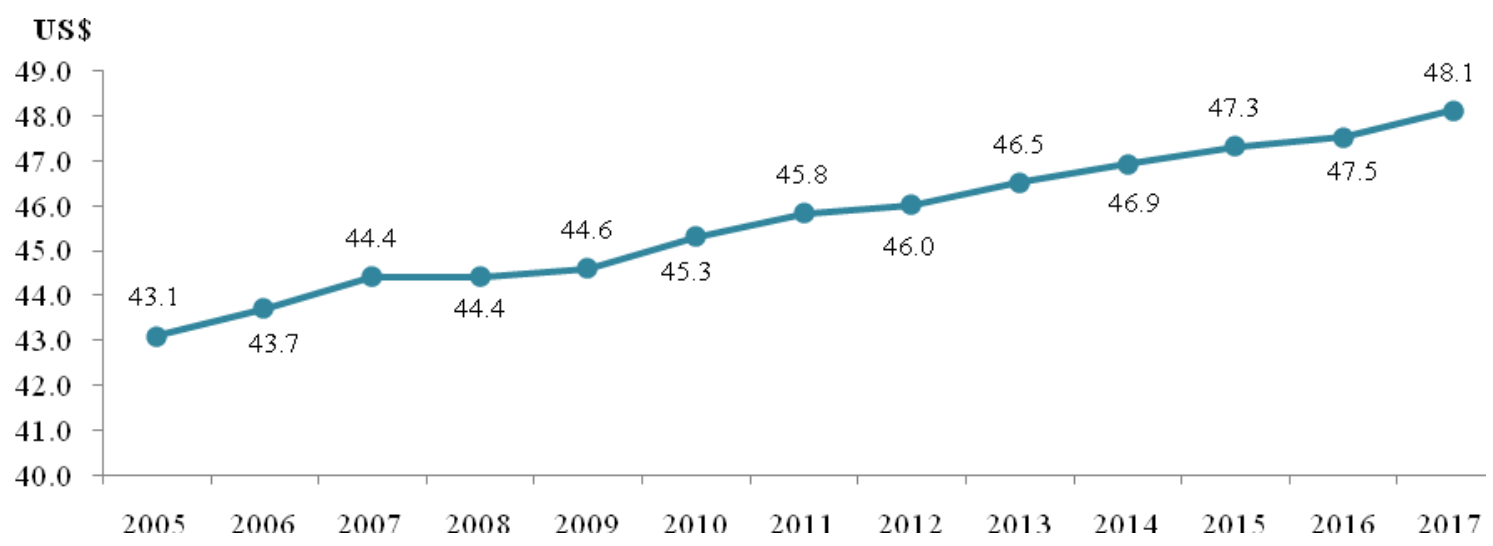

Fig. 1: GDP per hour worked for all OECD countries, (in US dollars), constant prices 2010 and PPPs, 20052017. Source: doi: $10.1787 / 1439 \mathrm{e} 590$-en

Table 2. Descriptive statistics of the variables for all OECD countries, 2005-2017

\begin{tabular}{|l|c|c|c|c|}
\hline Variable & Mean & Std. Dev. & Min. Mean & Max. Mean \\
\hline LP & 44.3384 & 15.7635 & 18.4483 & 80.0583 \\
\hline HW & 1745.097 & 201.43 & 1386.62 & 2256.28 \\
\hline LCH & 3.2915 & 3.8992 & 0.2310 & 10.0757 \\
\hline WAG & 37771.67 & 12778.98 & 15700.87 & 60633.15 \\
\hline LFP & 72.3785 & 6.4809 & 52.3596 & 86.2019 \\
\hline FDI & 36.73819 & 77.0285 & 0.8378 & 305.0642 \\
\hline GDPC & 1.5492 & 3.4673 & -1.3064 & 4.5624 \\
\hline INF & 2.2719 & 2.2566 & 0.2510 & 8.4689 \\
\hline IND & 24.8959 & 5.7633 & 12.1710 & 35.1203 \\
\hline COR & 1.2452 & 0.7985 & -0.4443 & 2.3579 \\
\hline
\end{tabular}

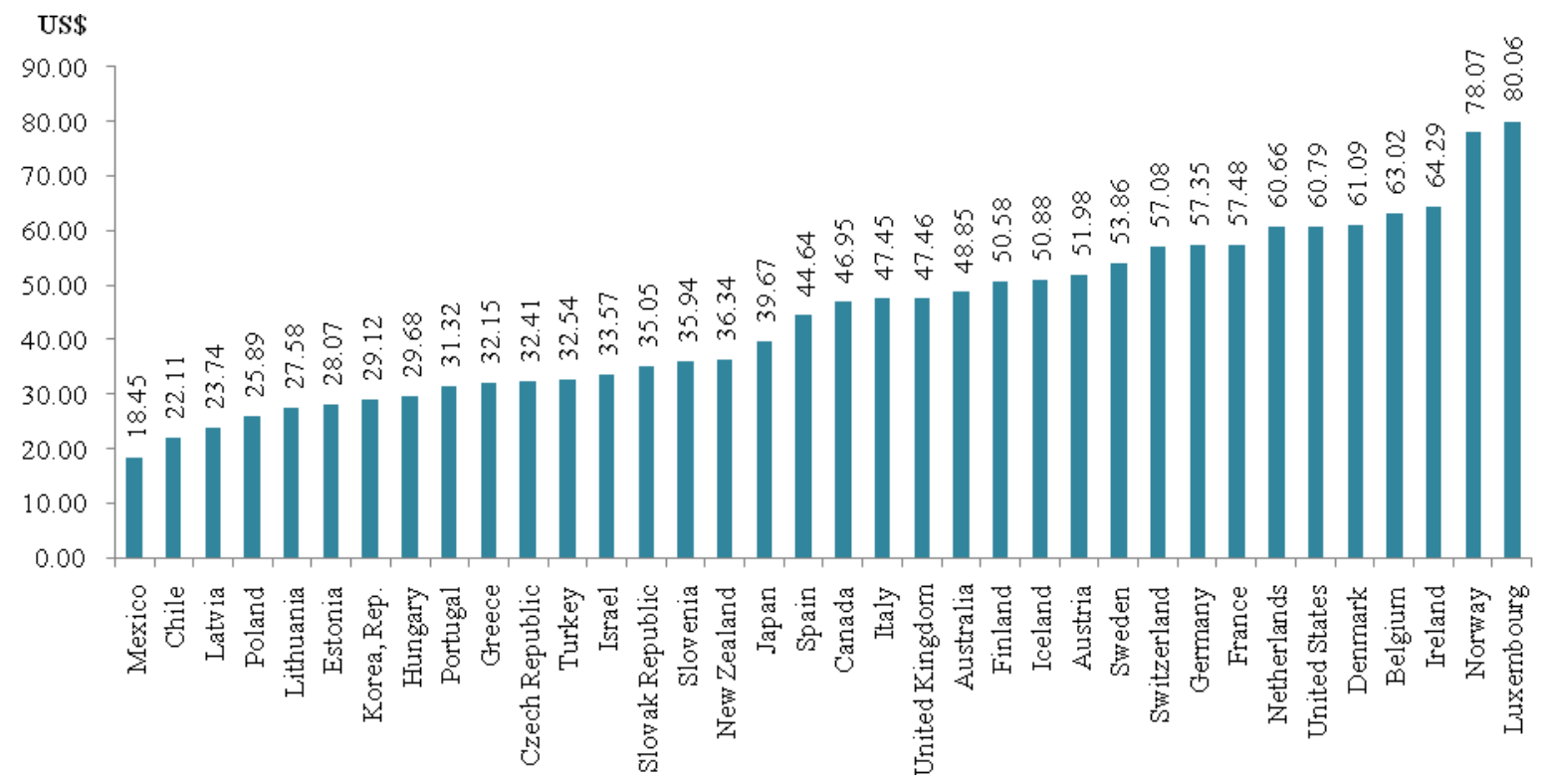


Fig. 2: GDP per hour worked, (in US dollars), constant prices 2010 and PPPs, 2005-2017

\subsection{Multicollinearity and Unit Root Tests}

We will begin by using panel unit root tests to make sure that the continuous variables used in our model are stationary. Fisher Type test is used because it does not require a balanced panel. As can be seen from Table 3, the null hypothesis of unit root has not been rejected for some variables. The first difference for these variables may make them stationary. Differencing is the process, which uses to transform data with a unit root; it is performed by subtracting previous value in the time series from the current value [30].

Table 3 shows that the test strongly rejects the null hypothesis of all the panels contain unit root for the following variables: $\mathrm{LCH}$, LFP, FDI, GDPC, INF, and COR. However, regarding the other variables, the null hypothesis has been rejected at the first difference of these variables.

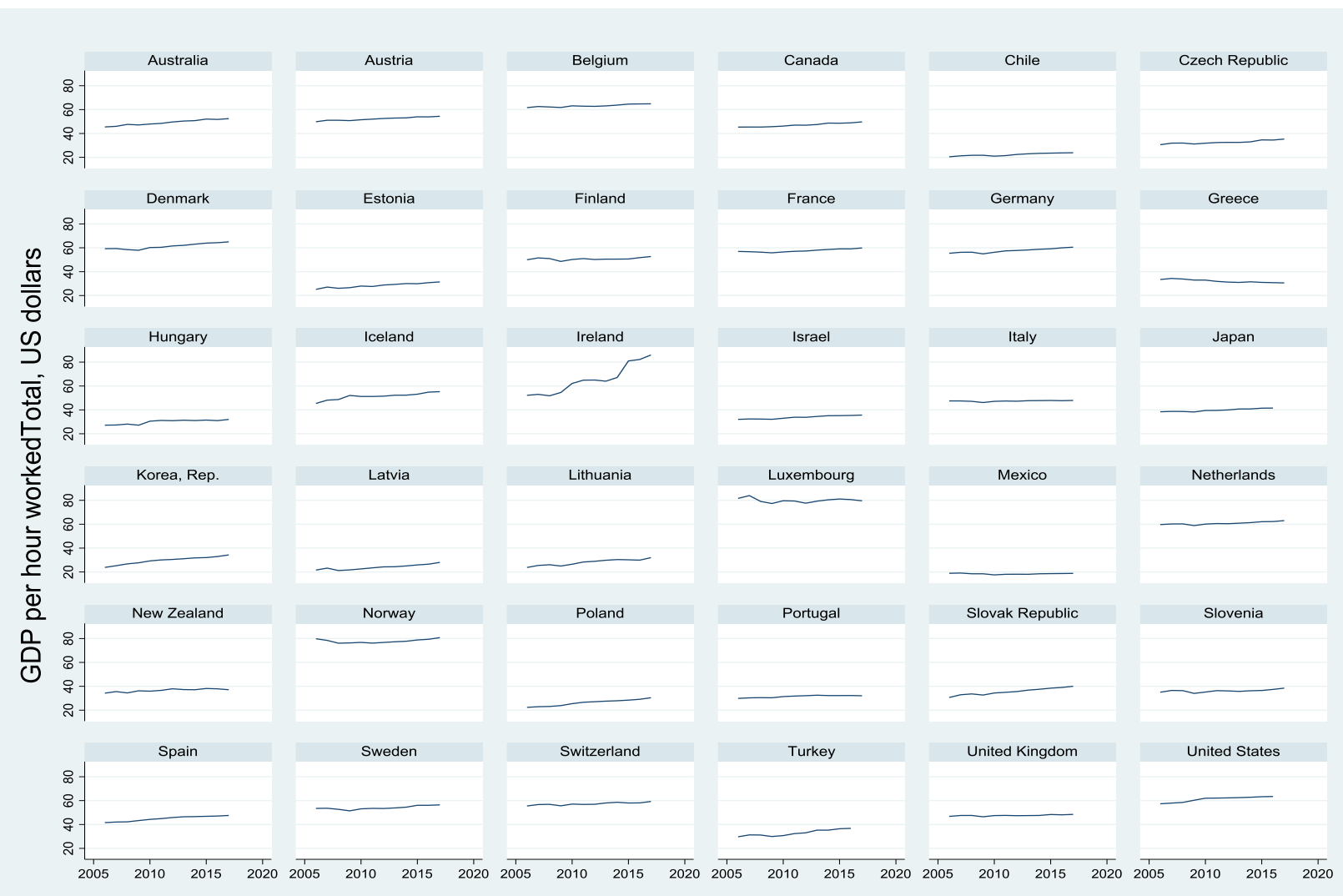

Fig. 3: Trend of GDP per hour worked according to country, constant prices 2010 and PPPs, 2005-2017

Table 3. Panel unit root test

\begin{tabular}{|l|c|c|c|c|c|}
\hline \multirow{2}{*}{ Variable } & \multicolumn{2}{|c|}{ Level } & \multicolumn{2}{c|}{ First Difference (D.) } & \multirow{2}{*}{$\begin{array}{c}\text { Integration } \\
\text { (degree) }\end{array}$} \\
\cline { 2 - 5 } & Statistic & p-value & Statistic & p-value & I (1) \\
\hline LP & 39.8839 & 0.9992 & 350.6702 & 0.0001 & I (1) \\
\hline HW & 77.6711 & 0.2476 & 366.7302 & 0.0001 & I $(0)$ \\
\hline WAG & 138.7033 & 0.0001 & ---- & ---- & I (1) \\
\hline LFP & 66.2387 & 0.6053 & 170.7903 & 0.0001 & I $(0)$ \\
\hline FDI & 121.9837 & 0.0002 & --- & ---- & I $(0)$ \\
\hline GDPC & 252.7371 & 0.0001 & --- & ---- & I $(0)$ \\
\hline INF & 192.9562 & 0.0001 & ---- & ---- & I $(0)$ \\
\hline
\end{tabular}




\begin{tabular}{|l|c|c|c|c|c|}
\hline IND & 59.5732 & 0.8521 & 378.1686 & 0.0001 & I (1) \\
\hline COR & 115.1672 & 0.0009 & ---- & ---- & I (0) \\
\hline
\end{tabular}

The second step of data processing is to try to make sure there is not multicollinearity among independent variables at levels, to make sure there is not an exact (or nearly exact) linear relation among two or more of the independent variables. multicollinearity is a type of disturbance in the data. If it presents in the data, the statistical inferences about the data may not be reliable. It can create inaccurate estimates of the regression coefficients, inflate the standard errors of the regression coefficients, deflate the partial t-tests for the regression coefficients, give false non-significant $\mathrm{p}$ values, and degrade the predictability of the model $[23,24,31]$.

Some of the common methods used for detecting multicollinearity include:

1. Pearson correlation matrix among pairs of predictor variables of the study, by checking the off-diagonal elements in $\left(\mathrm{X}^{\prime} \mathrm{X}\right)$. If regressors $\mathrm{X}_{\mathrm{i}}$ and $\mathrm{X}_{\mathrm{j}}$ are nearly linearly correlated, then $\left|\mathrm{r}_{\mathrm{ij}}\right|$ will be near unity.

2. The variance Inflation Factors (VIF) for each term in the model measures how much the variance of an estimated regression coefficient is inflated by the existence of correlation among the predictor variables in the model. In most of empirical studies, the general rule of thumb is that VIFs exceeding 5 warrant further investigation, while VIFs exceeding 10 are signs of serious multicollinearity requiring correction.

From Table 4, we can suggest no general concern about multicollinearity because the independent variables do not exhibit high correlations, and The VIF values for all predictors are less than 5 .

Table 4. Pearson correlation matrix and VIF

\begin{tabular}{|l|c|c|c|c|c|c|c|c|c|}
\hline Variable & D.HW & LCH & D.WAG & LFP & FDI & GDPC & INF & D.IND & COR \\
\hline D.HW & 1 & & & & & & & & \\
\hline LCH & -0.077 & 1 & & & & & & & \\
\hline D.WAG & 0.052 & $0.51^{* *}$ & 1 & & & & & & \\
\hline LFP & 0.090 & -0.041 & $0.16^{* *}$ & 1 & & & & & \\
\hline FDI & 0.090 & -0.089 & -0.008 & $0.10^{* *}$ & 1 & & & & \\
\hline GDPC & $0.30^{* *}$ & $0.43^{* *}$ & $0.289^{* *}$ & $-0.12^{* *}$ & 0.005 & 1 & & & \\
\hline INF & 0.055 & $0.50^{* *}$ & $-0.21^{* *}$ & $-0.34^{* *}$ & -0.063 & $0.13^{* *}$ & 1 & & \\
\hline D.IND & $0.27 * *$ & 0.007 & 0.029 & -0.050 & 0.064 & $0.53 * *$ & 0.017 & 1 & \\
\hline COR & 0.035 & $-0.12^{* *}$ & $0.12^{* *}$ & $0.71^{* *}$ & $0.18^{* *}$ & $-0.12^{* *}$ & $-0.24 * *$ & -0.042 & 1 \\
\hline VIF & $\mathbf{1 . 4 3}$ & $\mathbf{3 . 9 6}$ & $\mathbf{2 . 4 3}$ & $\mathbf{2 . 2 0}$ & $\mathbf{1 . 0 6}$ & $\mathbf{2 . 3 8}$ & $\mathbf{2 . 2 2}$ & $\mathbf{1 . 7 1}$ & $\mathbf{2 . 2 4}$ \\
\hline
\end{tabular}

Note: $* *$ p-value $<0.05$.

\subsection{Estimated Panel Data Models}

It is well-known that pooled OLS model disregards unobserved country heterogeneity. Therefore, as the next step, we employ FE and RE models. If unobserved country heterogeneity is correlated with the included regressors, FE estimators are unbiased and consistent, therefore, it will be the appropriate choice. While, RE model will be the appropriate choice if the unobserved country heterogeneity can be assumed to be uncorrelated with the included regressors. The formulations of the $\mathrm{FE}$ and $\mathrm{RE}$ models, respectively, are

$$
\begin{gathered}
\text { D. } \mathrm{LP}_{\text {it }}=\alpha_{\mathrm{i}}+\beta_{1} \mathrm{D} \cdot \mathrm{HW}_{\mathrm{it}}+\beta_{2} \mathrm{LCH}_{\mathrm{it}}+\beta_{3} \mathrm{D} \cdot \mathrm{WAG}_{\mathrm{it}}+\beta_{4} \mathrm{LFP}_{\mathrm{it}}+\beta_{5} \mathrm{FDI}_{\mathrm{it}}+\beta_{6} \mathrm{GDPC}_{\mathrm{it}}+\beta_{7} \mathrm{INF}_{\mathrm{it}}+\beta_{8} \mathrm{D} \cdot \mathrm{IND}_{\mathrm{it}} \\
+\beta_{9} \mathrm{COR}_{\mathrm{it}}+\mathrm{u}_{\mathrm{it}} ;
\end{gathered}
$$




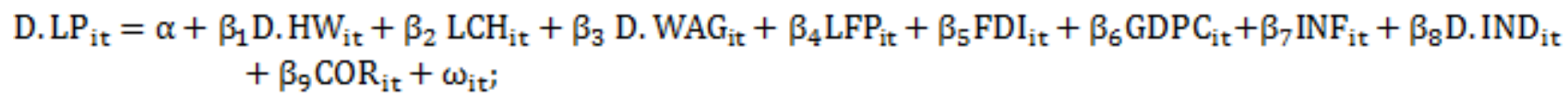

The FE within group model is estimated. The FE within group model is the most popular and is the default model of FE panel data regression in many software packages. RE model is estimated by GLS method. Table 5 reports the results of the three different specifications. Three specification tests are used in this study to identify the appropriate model among the above three models. First, the group effect test is applied to determine whether the FE model is better than the pooled OLS model, which is the case of rejection of the null hypothesis of this test. Then the LM test is conducted to decide between the RE model and the pooled OLS model. The rejection of the null hypothesis of the LM test indicates that RE model is better than pooled model. The pooled OLS model is the appropriate model in case of the failure to reject the null hypotheses in both of the above tests. On the other hand, when both null hypotheses of the group effect test and the LM test are rejected, the Hausman test will be applied to select between the two models.
From Table 5, the null hypotheses of the group effect and LM tests are rejected. Then we conducted the Hausman test. Based on the result of the Hausman test, we conclude that the RE model is appropriate model. In this stage, we should test the heteroskedasticity and serial correlation problems in the RE model using the Wald [32] test and Wooldridge [33] test, respectively. The results of the two tests indicate that the model have the two problems, because the p-values $(0.0001$ and 0.002$)$ of the two tests less than 0.05 .

To get an efficient estimation for the RE model in the presence heteroskedasticity and serial correlation problems, we estimated the RE model (see Table 5) by the feasible generalized least squares (FGLS) estimator [20] (using "xtgls" command), because the FGLS allows estimation in the presence of first order autocorrelation within panels and heteroskedasticity across panels by providing a good and appropriate estimation of the

$\Omega$ matrix.

Table 5. Results of estimated panel data models

\begin{tabular}{|c|c|c|c|}
\hline Variable & Pooled Model & FE Model & RE Model \\
\hline D.HW & $-0.01613 * * *$ & $-0.01568^{* * *}$ & $-0.01395^{* * *}$ \\
\hline LCH & 0.01377 & 0.00152 & -0.00014 \\
\hline D.WAG & -0.00009 & -0.00005 & -0.00002 \\
\hline LFP & $-0.02435^{*}$ & $-0.12325^{* * *}$ & $-0.01602 *$ \\
\hline FDI & 0.00048 & -0.00056 & -0.00050 \\
\hline GDPC & $0.18597 * * *$ & $0.17846 * * *$ & $0.21705^{* * *}$ \\
\hline INF & $-0.07913^{* *}$ & $-0.09039 * * *$ & $-0.05994 * * *$ \\
\hline D.IND & $0.22438 * * *$ & $0.21822 * * *$ & $0.13163 * * *$ \\
\hline COR & $0.21345 * *$ & 0.64179 & $0.16011 * * *$ \\
\hline Constant & $1.84879 *$ & $8.60365 * * *$ & $1.22833 * *$ \\
\hline \multicolumn{4}{|c|}{ I. Specification Tests } \\
\hline Group Effect Test & - & $2.04 * * *$ & --------- \\
\hline LM Test & --------- & ---------- & $8.33 * * *$ \\
\hline Hausman Test & --------- & \multicolumn{2}{|c|}{$\mathrm{H}=12.83$ with $\mathrm{p}$-value $=0.118$} \\
\hline \multicolumn{4}{|c|}{$\begin{array}{l}\text { II. Heteroskedasticity and Serial Correlation Tests } \\
\end{array}$} \\
\hline Wald Test & \multicolumn{3}{|c|}{$\chi^{2}=23.743$ with $\mathrm{p}$-value $=0.0001$} \\
\hline Wooldridge Test & \multicolumn{3}{|c|}{$\mathrm{F}=11.283$ with $\mathrm{p}$-value $=0.0020$} \\
\hline
\end{tabular}

Note: $*$ p-value $<0.10 ; * *$ p-value $<0.05 ; * * *$ p-value $<0.01$ 


\subsection{Discussion of Results}

Based on all applied previous tests, we select the RE panel data model for our data. The results of the RE model, in Table 5, show that the following variables have significant impact on labor productivity:

- Average annual hours worked has a negative significant impact on labor productivity at $(0.01)$ level. This result is consistent with the findings of [12] who attributed this effect to the fact that the level of attention and performance decreases as the individual gets tired and tired. However, there are two opposite opinion in literature to describe the effect of average annual hours worked on labor productivity. On the one hand, longer working hours can lead to higher productivity if a worker faces fixed set-up costs and fixed unproductive time during the day, or if longer working hours lead to better utilization of capital goods [34]. On the other hand, worker performance could decreases after a number of hours worked, so that the marginal effect on productivity of an extra hour per worker starts decreasing $[35,36]$.

- Labor force participation rate has a negative significant effect on labor productivity at $(0.10)$ level. This finding is consistent with [15]. Economic studies assert that there is negative relationship between LFP and productivity growth, at least in the short-term. The main causes for this negative relation are that new workers may lack practical skills and that they take a long time to become fully productive. In additional, older workers may suffer from slightly lower physical abilities and cognitive capacities, although this may be compensated by higher levels of experience and social intelligence. On balance, a higher participation of older workers, or an extension of their work life, is not likely to contribute to productivity growth [37].

- Annual growth rate of GDP per capita, perhaps the most widely used and well known measure of living standards, has a positive significant impact on labor productivity at (0.01) level. This finding is consistent with [38].

- Inflation rate, which is a proxy for economic stability, has a negative significant impact on labor productivity at (0.01) level. This finding is consistent with [15] who explained this result as inflation rate raises the uncertainty level in economy and which impedes investment. In addition, some studies were mentioned that inflation reduced the incentive to work, and distorted the informational content of relative price levels.

- Value added of industry has a positive significant impact on labor productivity at (0.01) level.

- Control of corruption, which is a proxy for institutional quality, has a positive significant impact on labor productivity at (0.01) level. As mentioned in the literature, the control of corruption plays a significant role in increasing productivity. If corruption is not controlled, this will lead to restriction of market access, weak property rights, and increasing uncertainty, thus eroding work incentives. Weak property rights are an alarm sign of corrupt governments and discourage investment in new ideas, where firms face higher business costs in light of the spread of corruption. In addition, the spread of bribes raises the cost of new projects. If permits can only be purchased with an expensive bribe, it is difficult for firms to enter new markets. As well, poor or low-quality infrastructure increases transportation costs [39].

\section{Conclusions}

This study empirically analyses the effect of some factors on labor productivity in 36 OECD countries during the period from 2005 to 2017 by utilizing panel data approach. The results indicate that the "RE model" is the appropriate model to analysis this data. Our finding reveals that:

1. Average annual hours worked have negative significant impact on labor productivity. The level of performance could decrease, when the individual works too much.

2. High labor force participation rates are associated with low labor productivity.

3. Annual growth rate of GDP per capita has a positive significant impact on labor productivity.

4. High level of inflation rates impact negatively labor productivity in OECD economies as price volatility in an economy leads to low investment, economic growth, and then low levels of productivity.

5. More value added of industry lead to more labor productivity.

6. The economies willing to control the levels of corruption will be much more productive than economies constrained by the high levels of corruption.

In the end, we can say that more studies are needed to discover and identify more effective mechanisms that can help countries in increasing 
the rates of labor productivity and growth rates of GDP. We suggest studying the impact of indicators of institutional quality at country level which are used in assessment of the government's ability to carry out its declared programs, and control of the corruption within the political system, such as "voice and accountability, political stability, government effectiveness, regulatory quality, rule of law, and control of corruption". In addition to some other economic factors, such as "the governmental expenditure on information and communication technology, gross capital formation, and openness indicators".

Future research also could follow a number of promising paths for identifying the underlying determinants of labor productivity whether at country-level or firm-level in OECD countries, by using different statistical methods such as dynamic and/or spatial panel data models.

\section{Acknowledgment:}

The authors thank the "Arrowad Group" for supporting this research, especially Dr. Saad bin Khalaf and Dr. Ahmed Al Mulaiki.

References:

[1] Abonazel, M. R., \& Abd-Elftah, A. I. (2019). Forecasting Egyptian GDP using ARIMA models. Reports on Economics and Finance, 5(1), 35-47.

[2] Abonazel, M. R., \& Shalaby, O. A. (2020). Using dynamic panel data modeling to study net FDI inflows in MENA countries. Studies in Economics and Econometrics, 44(2), 1-28.

[3] Abonazel, M. R., Awwad, F. A., Nwuju, K., Lukman, A.F., Lekara-Bayo, I. B., \& Atanu, E. Y. (2021). Long-Run Determinants of Nigerian Inflation Rate: ARDL Bounds Testing Approach. WSEAS Transactions on Business and Economics, 18, 1370-1379.

[4] Organization for Economic Co-operation and Development. (2019). OECD Compendium of Productivity Indicators. OECD Publishing

[5] Irmatova, Z. (2016). Managerial Analysis in Labor Productivity and Utilization: New Methods in Modern Labour Relations. European Journal of Business and Management, 8(24), 81-85.

[6] Youssef, A. \& Abonazel, M. (2017). Alternative GMM estimators for first-order autoregressive panel model: An improving efficiency approach. Communications in Statistics-Simulation and Computation, 46(4), 3112-3128.
[7] Abonazel, M. (2018). Different estimators for stochastic parameter panel data models with serially correlated errors. Journal of Statistics Applications \& Probability, 7(3): 423-434.

[8] Abonazel, M. (2019). Generalized estimators of stationary random-coefficients panel data models: asymptotic and small sample properties. Revstat Statistical Journal, 17(4): 493-521.

[9] Youssef, A. H., Abonazel, M. R., \& Ahmed, E. G. (2021). The performance of count panel data estimators: a simulation study and application to patents in Arab countries. Journal of Mathematical and Computational Science, 11(6), 8173-8196.

[10] El-Masry, A. M., Youssef, A. H., \& Abonazel, M. R. (2021). Using logit panel data modeling to study important factors affecting delayed completion of adjuvant chemotherapy for breast cancer patients. Communications in Mathematical Biology and Neuroscience, 2021, Article-ID 48.

[11] Cui, D., Wei, X., Wu, D., Cui, N., and Nijkamp, P. (2018). Leisure Time and Labor Productivity: A New Economic View Rooted from Sociological Perspective. Economics Discussion Papers.

[12] Policardo, L., Punzo, L. F., and Carrera, E. J. S. (2018). Wage Inequality and Labor Productivity in OECD Countries. Discussion Paper.

[13] Serfraz, A. (2018). Foreign Direct Investment Inflows and Labor Productivity in Pakistan: A Sector-Wise Panel Cointegration Analysis. Asian Journal of Economics and Empirical Research, 5(1), 1-18.

[14] Schubert, T., and Neuhäusler, P. (2018). Can Depleting Technological Opportunities Explain the Stagnation of Productivity? Panel Data Evidence for 11 OECD Countries. Studien Zum Deutschen Innovations System.

[15] Choudhry, M. T. (2009). Determinants of Labor Productivity: An Empirical Investigation of Productivity Divergence. ResearchGate.

[16] Korkmaz, S., and Korkmaz, O. (2017). The Relationship between Labor Productivity and Economic Growth in OECD Countries. International Journal of Economics and Finance, 9(5), 71-76.

[17] Salinas-Jimenez, M. D. M., and SalinasJimenez, J. (2006). Corruption and Productivity Growth in OECD Countries. In Ersa Conference Papers, European Regional Science Association. 
[18] Gujarati, D. N. and Porter, D. C. (2008). Basic Econometrics. 5th Ed., the McGraw-Hill Irwin, New York.

[19] Baltagi, B. H. (2005). Econometric Analysis of Panel Data. 3rd Ed., John Wiley and Sons, England.

[20] Greene, W. (2010). Econometric Analysis. Prentice Hall, United States of America.

[21] Cameron, A. C., and Trivedi, P. K. (2005). Micro-econometrics Methods and Applications. Cambridge University Press, New York.

[22] Balestra, P., and Krishnakumar, J. (2008). Fixed Effects Models and Fixed Coefficients Models. In The Econometrics of panel data (pp. 23-48). Springer, Berlin, Heidelberg.

[23] Dawoud, I., \& Abonazel, M. R. (2021). Robust Dawoud-Kibria estimator for handling multicollinearity and outliers in the linear regression model. Journal of Statistical Computation and Simulation, 91(17), 36783692.

[24] Abonazel, M. R., \& Taha, I. M. (2021). Beta ridge regression estimators: simulation and application. Communications in StatisticsSimulation and Computation, 1-13.

[25] Baltagi, B. H., Matyas, L., and Sevestre, P. (2008). Error Components Models. In The Econometrics of Panel Data (pp. 49-87). Springer, Berlin, Heidelberg.

[26] Breusch, T.S. and Pagan, A.R. (1980). The Lagrange Multiplier Test and Its Applications to Model Specification in Econometrics. Review of Economic Studies, 47, 239-253.

[27] Hausman, J.A. (1978). Specification Tests in Econometrics. Econometrica, 46, 1251-1271.

[28] Maddala, G. S. and Wu, S. (1999). A Comparative Study of Unit Root Tests with Panel Data and A New Simple Test. Oxford Bulletin of Economics and Statistics. Special Issue, 631-652.

[29] Ahmad, N., Lequiller, F., Marianna, P., Pilat, D., Schreyer, P., and Wolfl, A. (2003). Comparing Growth in GDP and Labour Productivity: Measurement Issues.

[30] Butler, M. and Kazakov, D. (2011). The Effects of Variable Stationarity in a Financial TimeSeries on Artificial Neural Networks. Computational Intelligence for Financial Engineering and Economics (CIFEr), IEEE Symposium, Paris, France. 1-8.

[31] Paul, R. K. (2006). Multicollinearity: Causes, Effects and Remedies. M. Sc. Thesis, Indian Agricultural Statistics Research Institute, New Delhi, India.
[32] Shehata, E. (2013). XTREGHET: Stata module to estimate MLE Random-Effects with Multiplicative Heteroscedasticity Panel Data Regression. Statistical Software Components, Boston College Department of Economics.

[33] Wooldridge, J. M. (2002). Econometric analysis of cross section and panel data MIT press. Cambridge, MA, 108.

[34] Feldstein, M. S. (1967). Specification of the Labour Input in the Aggregate Production Function. Review of Economic Studies, 34, 375-386.

[35] Pencavel, J. (2015). The Productivity of Working Hours. Economic Journal, 125, 20522076.

[36] Collewet, M., and Sauermann, J. (2017). Working Hours and Productivity. Labour Economics, 47, 96-106.

[37] De Jong, A., and Tsiachristas, A. (2008). Can Labor Force Participation Growth and Productivity Growth be Combined?. Spring Review by the SYSDEM Correspondent for the Netherlands, European Employment Observatory.

[38] Sharpe, A., Arsenault, J. F., and Harrison, P. (2008). The Relationship between Labour Productivity and Real Wage Growth in Canada and OECD Countries. Ottawa, Ontario: Centre for the Study of Living Standards.

[39] Kelly, C. (2014). Corruption and Productivity. M. Sc. Thesis, Clemson University.

\section{Creative Commons Attribution License 4.0 (Attribution 4.0 International, CC BY 4.0)}

This article is published under the terms of the Creative Commons Attribution License 4.0 https://creativecommons.org/licenses/by/4.0/deed.en US 